\title{
Prediksi Kemampuan Siswa Dalam Bersaing di Dunia Kerja Menggunakan Perbandingan Algoritma Naïve Bayes Dan K-Nearest Neighbor
}

\author{
Andi Purnomo*1, Ahmad Sururi², \\ 1,2, Program Studi Magister Ilmu Komputer Universitas Budi Luhur Jakarta \\ E-mail: ${ }^{* 1}$ andipurnomo999@gmail.com, ${ }^{2}$ ahmadsururi71@gmail.com
}

\begin{abstract}
Abstrak
SMK Yadika 5 Pondok Aren setiap tahunnya meluluskan +200 siswa/i nya. Semakin ketatnya persaingan dalam dunia kerja maka kualitas pendidikan pada siswa/i SMK Yadika 5 Pondok Aren adalah salah satu tujuan dari sekolah. Kurangnya daya serap lulusan SMK Yadika 5 Pondok Aren di dunia kerja menjadi salah satu persoalan penting yang harus segera diperbaiki, belum adanya sebuah pola dalam memprediksi siswa yang belum mampu memenuhi beberapa faktor dalam perekrutan karyawan di sebuah perusahaan maupun industri. Oleh karena itu, perlu adanya sebuah sistem untuk menemukan sebuah pola dalam melakukan prediksi siswa/i SMK Yadika dalam bersaing di dunia kerja. Salah satu Teknik pengolahan data yang dapat digunakan adalah Data Mining. Dalam pengolahan Data Mining ini peneliti menggunakan metode klasifikasi dengan algoritma Naïve Bayes dan membandingkan dengan algoritma K-Nearest Neighbor serta melakukan pengujian pada nilai precision, nilai recall, nilai akurasi. Berdasarkan pengujian yang telah dilakukan dalam penelitian ini mendapati hasil bahwa Algoritma Naïve Bayes memiliki Akurasi $97.66 \%$, Nilai Precision 100\%, dan Nilai Recall 97.59\% sedangkan Algoritma K-Nearest Neighbor mendapati hasil Nilai Akurasi $98.22 \%$, Nilai Precision $99.38 \%$, Nilai Recall $98.77 \%$. Dari hasil yang didapatkan maka algoritma Naïve Bayes dan K-Nearest Neighbor dapat diterapkan serta dijadikan suatu pola baru dalam memprediksi siswa dalam memenuhi beberapa faktor dalam perekrutan karyawan di sebuah perusahaan maupun industri.
\end{abstract}

Keywords - Data Mining, Algoritma Nä̈ve Bayes, Algoritma K-Nearest neighbor

\begin{abstract}
SMK Yadika 5 Pondok Aren annually graduates +200 students. The more intense competition in the world of work, the quality of education for students of SMK Yadika 5 Pondok Aren is one of the goals of the school. The lack of absorption of graduates of SMK Yadika 5 Pondok Aren in the world of work is one of the important problems that must be corrected immediately, there is no pattern in predicting students who have not been able to overcome several factors in employees in an industrial company. Therefore, it is necessary to have a system to find a pattern in predicting Yadika Vocational High School students in competing in the world of work. One of the data processing techniques that can be used is Data Mining. In processing Data Mining, the researcher uses a classification method with the Naïve Bayes algorithm and compares it with the K-Nearest Neighbor algorithm and tests the precision value, recall value, and accuracy value. Based on the tests that have been carried out in this study found the results that the Nä̈ve Bayes Algorithm has 97.66\% Accuracy, 100\% Precision Value, and 97.59\% Recall Value while the K-Nearest Neighbor Algorithm gets 98.22\% Accuracy Value, Precision Value $99.38 \%$, Recall value $98.77 \%$. From the results obtained, the Nä̈ve Bayes and K-Nearest Neighbor algorithms can be applied and a new pattern is applied in predicting students in fulfilling several factors in the achievement of employees in a company or industry.
\end{abstract}

Keywords - Data Mining, Algoritma Nä̈ve Bayes, Algoritma K-Nearest neighbor 


\section{PENDAHULUAN}

Perkembangan teknologi yang pesat di era modern ini sudah banyak memberikan manfaat dalam berbagai aspek, khususnya kontribusi untuk mempermudah pekerjaan manusia dalam bentuk komputerisasi. Dengan adanya perkembangan teknologi, sesuatu hal yang belum pernah terjadi akan sangat mudah untuk di prediksi dengan teknologi meskipun tingkat keakuratannya tidak mencapai $100 \%$.

Sekolah Menengah Kejuruan (SMK) merupakan salah satu lembaga pendidikan yang berupaya menciptakan sumber daya manusia yang memiliki kemampuan, keterampilan, dan keahlian sehingga lulusannya dapat mengembangkan keterampilannya agar dapat terjun dalam dunia kerja maupun untuk melanjutkan ke jenjang pendidikan yang lebih tinggi. SMK Yadika 5 Pondok Aren merupakan salah satu instansi Pendidikan Sekolah Menengah Kejuruan ( SMK ) yang berkawasan di Kecamatan Pondok Aren, yang setiap tahunnya SMK Yadika 5 Pondok Aren meluluskan + 200 siswa/i nya.

Terdapat beberapa faktor pada saat mengikuti perekrutan di perusahaan tersebut yang menjadi standar poin penilaian bagi calon karyawan dengan Pendidikan terakhir SMK/Sederajat, diantaranya ialah nilai rata-rata Ujian Kompetensi Kejuruan, Nilai Praktek Kerja Lapangan, disiplin, tanggung jawab, sikap, dan kemampuan komunikasi dalam team. Untuk memastikan bahwa siswa/i SMK Yadika 5 mendapatkan kesempatan bekerja setelah mereka lulus, maka SMK Yadika 5 dapat melakukan pengumpulan data berdasarkan hasil nilai mata pelajaran, nilai ujian akhir, nilai praktek kerja lapangan dan nilai perilaku keseharian dari setiap siswa/i mulai dari kelas 1 hingga kelas 3, dimana hasil dari proses pembelajaran tersebut setiap tahunnya akan diinput oleh wali kelas dari setiap masing- masing kelas, maka dengan data tersebut SMK Yadika 5 dapat melihat perkembangan dari siswa/i setiap tahunnya. Terdapat beberapa metode yang dapat digunakan untuk memprediksi kemampuan siswa/i SMK Yadika 5, salah satunya ialah penggunaan metode klasifikasi untuk mendapatkan sebuah informasi untuk pihak sekolah agar dapat mengarahkan, membimbing, serta memberikan motivasi kepada siswa/i SMK Yadika 5 yang belum memenuhi beberapa faktor dalam perekrutan karyawan di sebuah perusahaan maupun industri, agar mereka dapat bersaing dengan calon karyawan yang lainnya. Dalam penelitian ini peneliti mengidentifikasikan permasalahan yang terjadi ialah belum adanya suatu pola dalam memprediksi siswa yang belum mampu memenuhi beberapa faktor dalam perekrutan karyawan di sebuah perusahaan maupun industri berdasarkan nilai mata pelajaran hingga nilai perilaku keseharian.Dari permasalahan tersebut perlu adanya sebuah solusi untuk menemukan sebuah pola dalam melakukan prediksi siswa/i SMK Yadika dalam bersaing di dunia kerja, salah satu teknik pengolahan data yang dapat digunakan adalah Data Mining. Dalam pengolahan Data Mining ini peneliti menggunakan metode klasifikasi dengan algoritma Naïve Bayes dan membandingkan dengan algoritma K-Nearest Neighbor agar dapat mengetahui serta mengukur akurasi yang dihasilkan oleh algoritma tersebut.

Data Mining merupakan suatu istilah yang digunakan untuk menguraikan penemuan pengetahuan di dalam database. Data mining adalah proses menganalisa data dari perspektif yang berbeda dan menyimpulkannya menjadi informasi-informasi penting yang dapat dipakai untuk meningkatkan keuntungan, memperkecil biaya pengeluaran, atau bahkan keduanya. Secara teknis, data mining dapat disebut sebagai proses untuk menemukan korelasi atau pola dari ratusan atau ribuan field dari sebuah relasional database yang besar. data mining juga merupakan proses untuk menggali nilai tambah berupa informasi yang selama ini tidak diketahui secara manual dari suatu basis data. Informasi yang dihasilkan diperoleh dengan cara mengekstraksi dan mengenali pola yang penting atau menarik dari data yang terdapat dalam basis data (Nofriansyah et al,2016). Data mining berisi pencarian trend atau pola yang diinginkan dalam database besar untuk membantu pengambilan keputusan di waktu yang akan datang. Pola-pola ini dikenali oleh perangkat tertentu yang dapat memberikan suatu analisa data yang berguna dan berwawasan yang kemudian dapat dipelajari dengan lebih teliti, yang mungkin saja menggunakan perangkat pendukung keputusan lainnya (Mustafa et al, 2017).

Algoritma Naïve Bayes merupakan sebuah metode klasifikasi yang berdasar pada teorema Bayes. Metode pengklasifikasian ini menggunakan metode probabilitas dan statistik, Ciri utama dari Naive Bayes ini adalah asumsi yang sangat kuat akan independensi dari masing-masing kondisi atau kejadian (Mustafa et al, 2018). Keuntungan penggunaan algoritma Naïve Bayes adalah bahwa metode ini hanya membutuhkan jumlah data pelatihan ( Training Data ) yang kecil untuk menentukan estimasi parameter yang dibutuhkan dalam proses pengklasifikasian(Saleh, 2015). Naive bayes termasuk ke 
dalam pembelajaran supervised, sehingga pada tahapan pembelajaran dibutuhkan data awal berupa data pelatihan untuk dapat mengambil keputusan. Pada tahapan pengklasifikasian akan dihitung nilai probabilitas dari masing-masing label kelas yang ada terhadap masukan yang diberikan. Label kelas yang memiliki nilai probabilitas paling besar yang akan dijadikan label kelas data masukan tersebut. Naive bayes merupakan perhitungan teorema bayes yang paling sederhana, karena mampu mengurangi kompleksitas komputasi menjadi multiplikasi sederhana dari probabilitas. Selain itu, algoritma naive bayes juga mampu menangani set data yang memiliki banyak atribut (Sartika et al, 2017). Algoritma Naive Bayes memberikan suatu cara mengkombinasikan peluang terdahulu dengan syarat kemungkinan menjadi sebuah formula yang dapat digunakan untuk menghitung peluang dari setiap kemungkinan yang terjadi.

Pada penelitian sebelumnya Kusuma (2019) penggunaan Algoritma Naïve Bayes pada prediksi kemampuan lulusan SMK Buddhi Tangerang dapat memberikan hasil yang baik, karena memiliki nilai akurasi sebesar 98\% dan juga pada penelitian Khoirunnisa (2018) mengungkapkan bahwa tujuan dari metode klasifikasi data mining untuk meningkatkan keandalan hasil yang diperoleh dari data. Serta penggunaan Confusion Matrix sebagai evaluasi untuk mendapatkan nilai akurasi, recall, dan precision yang baik. Oleh Karena itu, diharapkan dengan penerapan metode klasifikasi data mining dengan Algoritma Naïve Bayes dan Algoritma K-Nearest Neighbor dapat memprediksi kemampuan siswa/i SMK Yadika 5 dalam memenuhi beberapa faktor perekrutan karyawan di sebuah perusahaan maupun industri, serta menghasilkan nilai akurasi yang baik agar dapat menjadi acuan dalam meningkatkan kualitas pembelajaran SMK Yadika 5 agar menjadi lebih baik. Dan dapat diterapkan serta dijadikan suatu pola baru dalam memprediksi siswa dalam memenuhi beberapa faktor dalam perekrutan karyawan di sebuah perusahaan maupun industri agar dapat memastikan siswa/i SMK Yadika 5 mendapatkan kesempatan bekerja setelah mereka lulus.

\section{METODE PENELITIAN}

Pada penelitian ini menggunakan metodologi CRIPS-DM untuk melakukan Analisa dan mengelola data. Tahapan penelitian ini dibagi ke dalam beberapa tahap yang dapat di lihat pada gambar berikut.

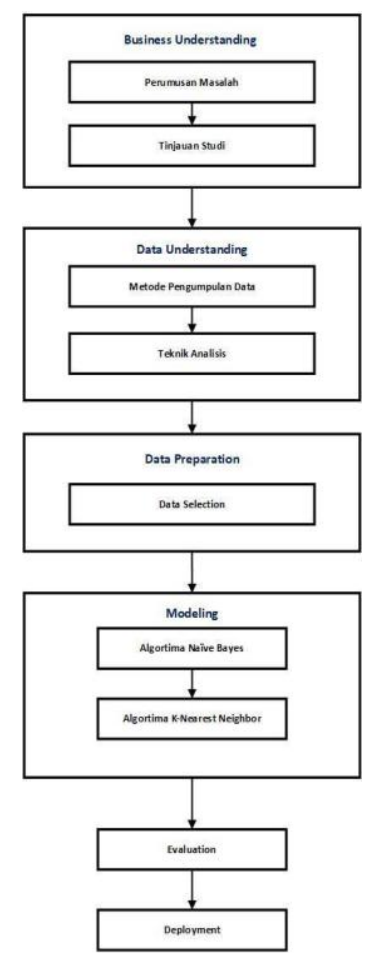

Gambar 1 Metode Penelitian 


\section{Perumusan Masalah}

Dalam penelitian ini peneliti mengidentifikasikan permasalahan yang terjadi ialah belum adanya suatu pola dalam memprediksi siswa yang belum mampu memenuhi beberapa faktor dalam perekrutan karyawan di sebuah perusahaan maupun industri berdasarkan nilai mata pelajaran hingga nilai perilaku keseharian.Dari permasalahan tersebut perlu adanya sebuah solusi untuk menemukan sebuah pola dalam melakukan prediksi siswa/i SMK Yadika dalam bersaing di dunia kerja, salah satu teknik pengolahan data yang dapat digunakan ialah Data Mining. Dalam pengolahan Data Mining ini peneliti menggunakan metode klasifikasi dengan algoritma Naïve Bayes dan membandingkan dengan algoritma K-Nearest Neighbor agar dapat mengetahui serta mengukur akurasi yang dihasilkan oleh algoritma tersebut.

\section{Tinjauan Studi}

Tinjauan Studi ini di lakukan untuk mendapatkan teori mengenai metode klasifikasi data mining,algoritma Nä̈ve bayes, Algoritma K-Nearest Neighbor yang terkait dengan rumusan permasalahan. Metode yang di lakukan penulis adalah membaca berbagai jurnal ilmiah terkait dengan metode klasifikasi Data Mining, Algoritma K-Nearest Neighbor dan algoritma Nä̈ve Bayes.Hasil dari langkah ini adalah literatur yang terkait dengan perumusan masalah.

\section{Pengumpulan Data}

Untuk mendapatkan sebuah informasi, maka tentu saja dibutuhkan sumber data yang akurat dalam penyusunannya. Untuk itu penulis melakukan pengumpulan data dengan mengambil langsung dari SMK Yadika 5 Pondok Aren. Data ini terdiri dari hasil penilaian siswa/i SMK Yadika 5 Pondok Aren.

\begin{tabular}{|c|c|c|c|}
\hline No & Tahun Ajaran & Keterangan & Jumlah \\
\hline 1 & $2016 / 2017$ & Alumni & 177 \\
\hline 2 & $2017 / 2018$ & Alumni & 176 \\
\hline 3 & $2018 / 2019$ & Alumni & 194 \\
\hline 4 & $2019 / 2020$ & Alumni & 151 \\
\hline 5 & $2020 / 2021$ & Kelas X & 171 \\
\hline & & Kelas XI & 157 \\
\hline & & Kelas XII & 169 \\
\hline \multicolumn{3}{|c|}{ Total } & 1195 \\
\hline
\end{tabular}

Gambar 2 Dataset Penelitian

Kemudian dilakukan Teknik analisis data yang bertujuan untuk mengatasi masalah yang ada berdasarkan data yang diperoleh. Analisis data yang dilakukan yaitu mengumpulkan data kuantitatif. Data kuantitatif tersebut yang nantinya akan diolah dan digunakan dalam penelitian ini.

\section{Data Selection}

Proses data selection ini dilakukan dengan tujuan memilih atribut yang relevan pada data untuk dapat dilakukan suatu analisis data. Pemilihan atribut tersebut di dasari oleh data yang diterima penulis dari SMK Yadika 5 Pondok Aren yang terdapat beberapa atribut

( variable ) yang berpengaruh kepada kemampuan siswa/i SMK Yadika 5 dalam bersaing di dunia kerja. Berikut atribut-atribut yang akan digunakan antara lain.

\begin{tabular}{|c|l|l|}
\hline No & Atribut & \multicolumn{1}{|c|}{ Keterangan } \\
\hline 1 & JK & Jenis Kelamin \\
\hline 2 & JUR & Jurusan \\
\hline 3 & UKK & Nilai Ujian Kenaikan kelas \\
\hline 4 & PROD & Nilai Mata Pelajaran Produktif \\
\hline 5 & PKL & Nilai Praktek Kerja Lapangan \\
\hline 6 & TJ & Nilai Tanggung Jawab \\
\hline 7 & DIS & Nilai Disiplin \\
\hline 8 & KOM & Nilai Komunikasi \\
\hline 9 & PRI & Nilai Prilaku \\
\hline 10 & KM & Nilai Keterampilan \\
\hline 11 & KET & Keterangan Mampu atau Belum Mampu \\
\hline
\end{tabular}

Gambar 3 Atribut yang Digunakan 


\section{Algortima Naive Bayes}

Algoritma Nä̈ve Bayes merupakan sebuah metode klasifikasi yang berdasar pada teorema Bayes. Metode pengklasifikasian ini menggunakan metode probabilitas dan statistik, Ciri utama dari Naive Bayes ini adalah asumsi yang sangat kuat akan independensi dari masing-masing kondisi atau kejadian(Mustafa et al, 2018).

\section{Algortima K-Nearest Neighbor}

$K$-Nearest Neighbor $(K-N N)$ merupakan sebuah metode untuk melakukan klasifikasi terhadap objek berdasarkan data pembelajaran yang jaraknya paling dekat dengan objek tersebut. K-NN termasuk algoritma supervised learning dimana hasil dari query instance yang baru diklasifikan berdasarkan mayoritas dari kategori pada K-NN(Syaliman et al,2017). K-Nearest Neighbor melakukan pendekatan untuk mencari kasus dengan menghitung kedekatan antara kasus baru dengan kasus lama, yaitu berdasarkan pada pencocokan bobot dari sejumlah fitur yang ada(Umaidah dan Purwantoro,2019).

\section{Evaluation}

Pada tahapan ini merupakan penerapan dari penelitian menggunakan metode klasifikasi data mining menggunakan Algoritma Nä̈ve Bayes dan Algoritma K-Nearest Neighbor yang di implementasikan pada sebuah sistem. Sistem ini dimulai dengan masukan berupa data training dan data uji dari user yang kemudian akan masuk ke dalam database sistem, kemudian akan dilakukan proses prediksi dengan metode klasifikasi data mining menggunakan algoritma Nä̈ve Bayes dan Algoritma K-Nearest Neighbor, Setelah proses prediksi selesai maka akan muncul hasil dari confusion matrix berupa akurasi, recall, precision dan hasil dari prediksinya.

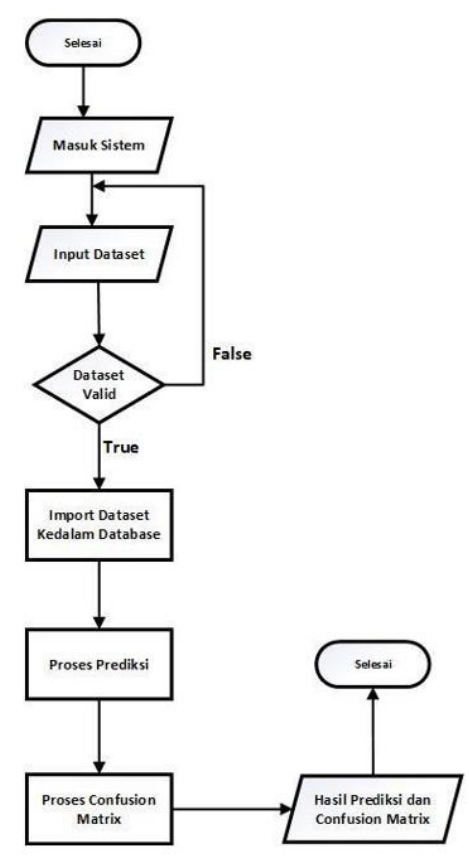

Gambar 4 Diagram Alur Perancangan

\section{Deployment}

Sistem ini terdiri dari beberapa proses utama yaitu Data cleaning, Data Selection, perhitungan Standar deviasi, perhitungan Mean, perhitungan probabilitas, perhitungan Densitass Gaus, Perhitungan Manhattan Distance dan melakukan pengujian menggunakan Confusion Matrix

\section{HASIL DAN PEMBAHASAN}

Lokasi penelitian ini dilakukan di SMK Yadika 5 Pondok aren. Tujuan dari penelitian ini adalah untuk memprediksi kemampuan siswa dan siswi SMK Yadika 5 Pondok aren falam bersaing di dunia 
kerja menggunakan perbandingan algoritma naïve bayes dan k-nearest. Dalam penelitian ada beberapa tahapan sebagai berikut.

\section{Pengumpulan Data}

Data yang dimasukan ke dalam database akan digunakan sebagai objek utama dalam penelitian ini. Sebagai sumber informasi yang akan dilakukan proses prediksi terhadap kemampuan siswa/I SMK Yadika 5 Pondok Aren menggunakan Algoritma Nä̈ve Bayes dan Algoritma K-Nearest Neighbor setelah itu akan dilakukan pengujian menggunakan Confusion Matrix untuk menentukan nilai Akurasi, Recall, Precision. Data yang penulis gunakan sebagai data model dan data uji ialah data berdasarkan gambar yang dapat dilihat pada gambar 5 .

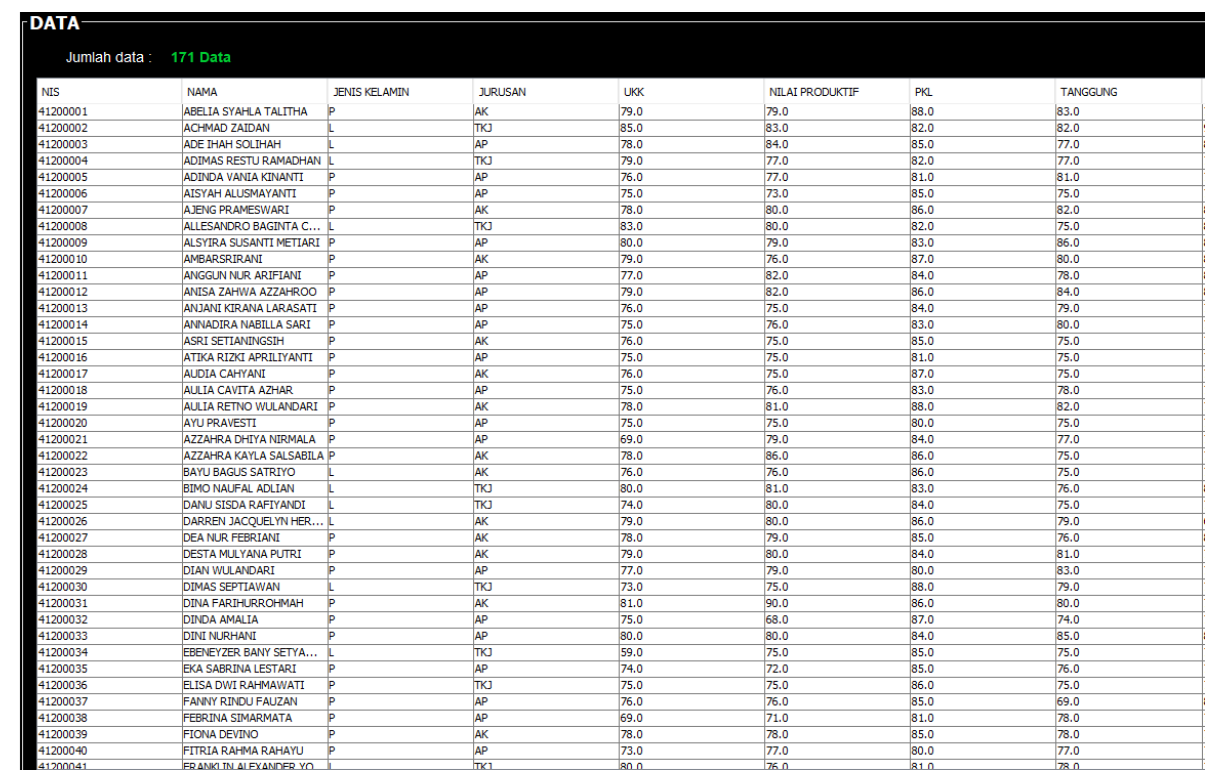

Gambar 5. Tampilan Dataset

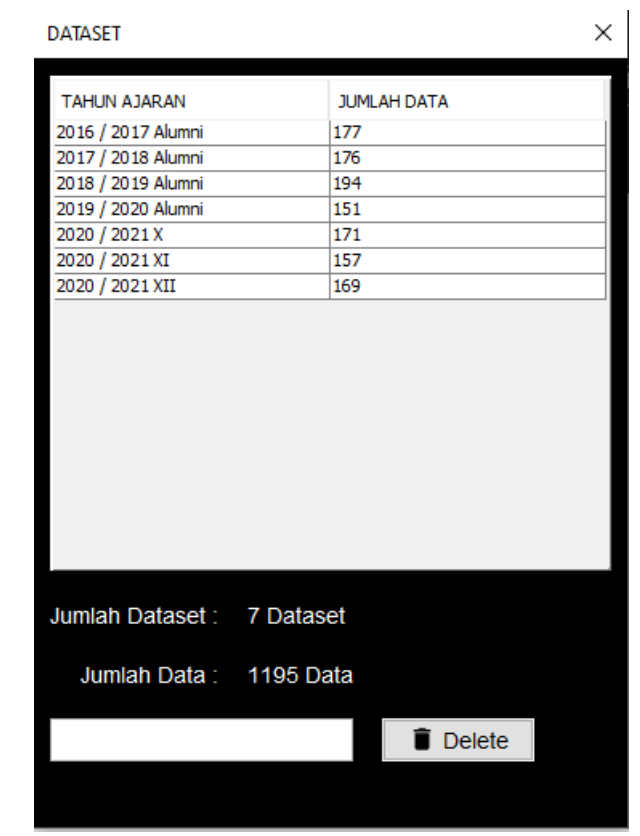

Gambar 6. Informasi Jumlah Dataset

Jumlah Dataset yang telah dimasukan kedalam database akan digunakan sebagai data model dan data uji. Dimana jumlah data model harus lebih banyak dibandingkan data uji agar dapat dilakukan proses prediksi kemampuan siswa/I dalam bersaing di dunia kerja.untuk jumlah Dataset yang sudah di masukan ke dalam database dapat dilihat pada gambar 6. 


\section{Pengujian Sistem}

Dalam tahapan ini, Sistem akan dijalankan dan diuji cobakan untuk mengetahui apakah sistem berjalan sesuai dengan hasil Analisa dan tujuan. Untuk mengetahui kemampuan sistem Prediksi kemampuan siswa/I dalam bersaing di dunia kerja yang telah dibangun dalam tesis ini, maka akan dilakukan pengujian dengan mengukur kualitas dari nilai akurasi, precision dan recall dari algoritma Nä̈ve Bayes dan Algoritma K-Nearest Neighbor. Manakah di antara kedua Algoritma tersebut yang mendapatkan nilai akurasi yang paling baik. Pada gambar 3 adalah jumlah dataset yang akan digunakan untuk melakukan pengujian dari Algoritma Nä̈ve Bayes dan Algoritma K-Nearest Neighbor.

\section{Klasifikasi Algoritma K-Nearest Neighbor}

Klasifikasi menggunakan Algoritma K-Nearest Neighbor berfungsi untuk memprediksi kemampuan siswa/I dalam bersaing didunia kerja menggunakan dataset yang belum memiliki keterangan mampu dan belum mampu. data model yang digunakan dalam pengujian ini merupakan dataset terdapat pada database, serta dataset uji yang digunakan dalam pengujian ini menggunakan 497 data yang berasal dari tahun ajaran 2020/2021 Kelas X, Kelas XI, dan Kelas XII dengan menggunakan Number of Nearest Neighbor ( K ) $=3$ dan Number of Nearest Neighbor ( K ) $=5$. Number of Nearest Neighbor ( K ) yang dapat digunakan ialah nilai dari angka ganjil apabila yang diinpukan selain dari nilai angka ganjil maka sistem akan menampilkan sebuah messages box yang dapat di lihat pada gambar 7.

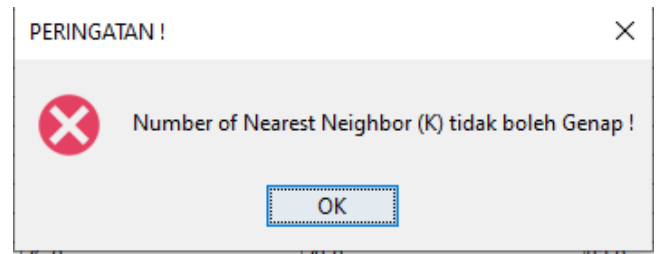

Gambar 7 Tampilan Messages Box

4. Klasifikasi Number of Nearest Neighbor $(K)=3$

Hasil dari pengklasifikasian menggunakan algoritma K-Nearest Neighbor Dengan Number of Nearest Neighbor $($ K $)=3$ pada tahun ajaran 2020/2021 Kelas XII mendapati hasil siswa yang di nyatakan mampu terdapat 162 siswa Hasil dari pengklasifikasian dapat di save untuk di masukan kedalam database serta akan di lakukan pengujian dengan data model untuk dapat melihat nilai dari akurasi, Precision dan Recall yang dihasilkan.

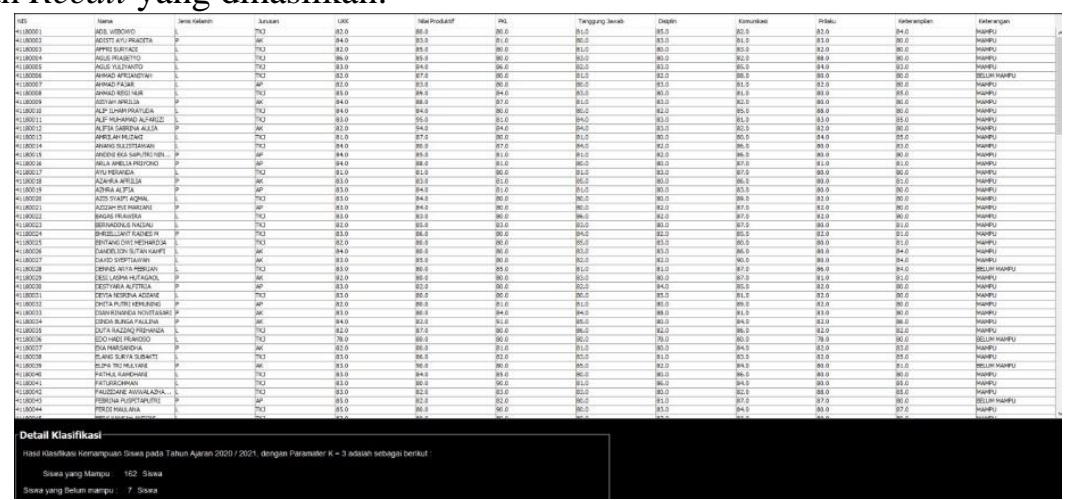

Gambar 8 Hasil Klasifikasi Kelas K=3 XII

\section{Klasifikasi Number of Nearest Neighbor $(K)=5$}

Hasil dari pengklasifikasian menggunakan algoritma K-Nearest Neighbor Dengan Number of Nearest Neighbor ( K ) = 5 pada tahun ajaran 2020/2021 Kelas XII mendapati hasil siswa yang di nyatakan mampu terdapat 166 siswa. Hasil dari pengklasifikasian dapat di save untuk di masukan kedalam database serta akan di lakukan pengujian dengan data model untuk dapat melihat nilai dari akurasi, Precision dan Recall yang dihasilkan. 


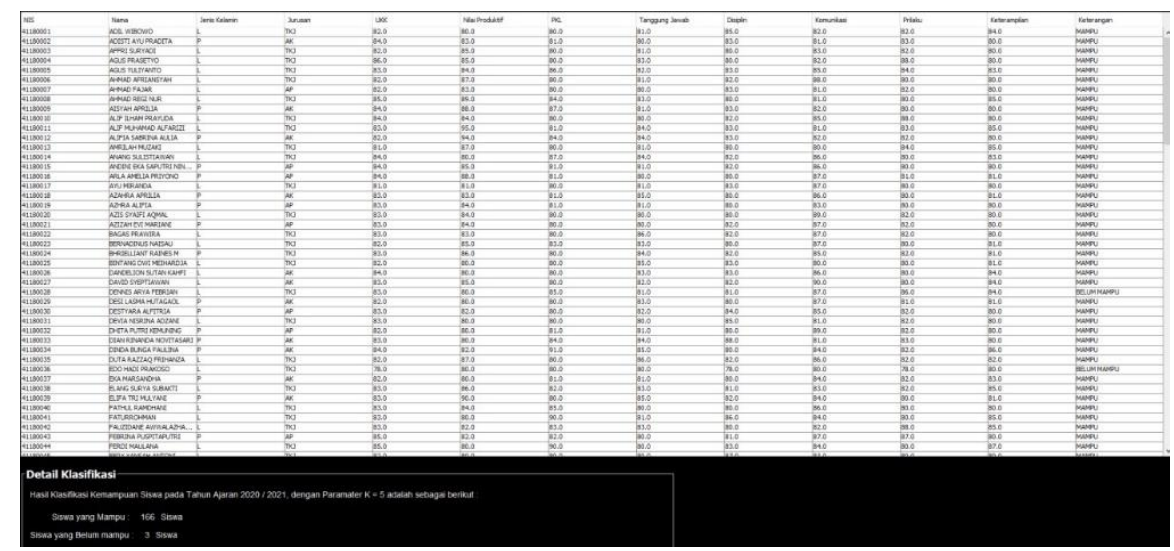

Gambar 9 Hasil Klasifikasi K= 5 Kelas XII

\section{Pengujian Algoritma K-Nearest Neighbor}

Pengujian menggunakan Algoritma K-Nearest Neighbor Menggunakan 521 Data Model dan Dataset Uji menggunakan tahun ajaran 2020/2021 Kelas ahun ajaran Kelas XII dengan total data 169 dapat dilihat pada gambar 10 .

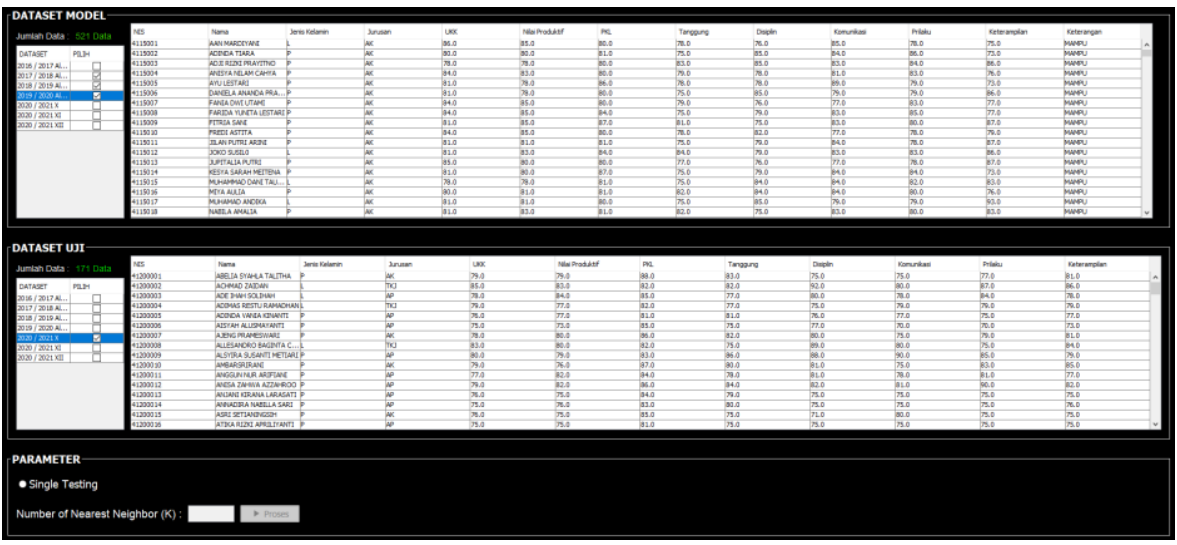

Gambar 10 Dataset Model dan Dataset Uji Algortima K-Nearest Neighbor

Keseluruhan data uji sebelumnya sudah dilakukan proses klasifikasi menggunakan parameter number of Nearest Neighbor ( K ) = 3 yang dapat dilihat pada gambar 5, dan gambar 6, number of Nearest Neighbor $(\mathrm{K})=5$ yang dapat di lihat pada gambar 8 .

\section{Pengujian Number of Nearest Neighbor $(K)=3$ Kelas XII}

Hasil dari pengujian menggunakan algortima K-Nearest Neighbor menggunakan number of Nearest Neighbor $(\mathrm{K})=3$ Pada Kelas XII dengan 521 data model dan 169 data uji mendapatkan hasil nilai aktual mampu yang di prediksikan mampu ( TP ) sebanyak 160 Siswa, nilai aktual mampu yang di prediksikan belum mampu ( FN ) sebanyak 2 siswa, Sementara nilai actual belum mampu yang di prediksikan mampu ( FP ) sebanyak 1 siswa dan nilai actual belum mampu yang di prediksikan belum mampu ( TN ) sebanyak 6 siswa yang dapat di lihat pada gambar 11. 


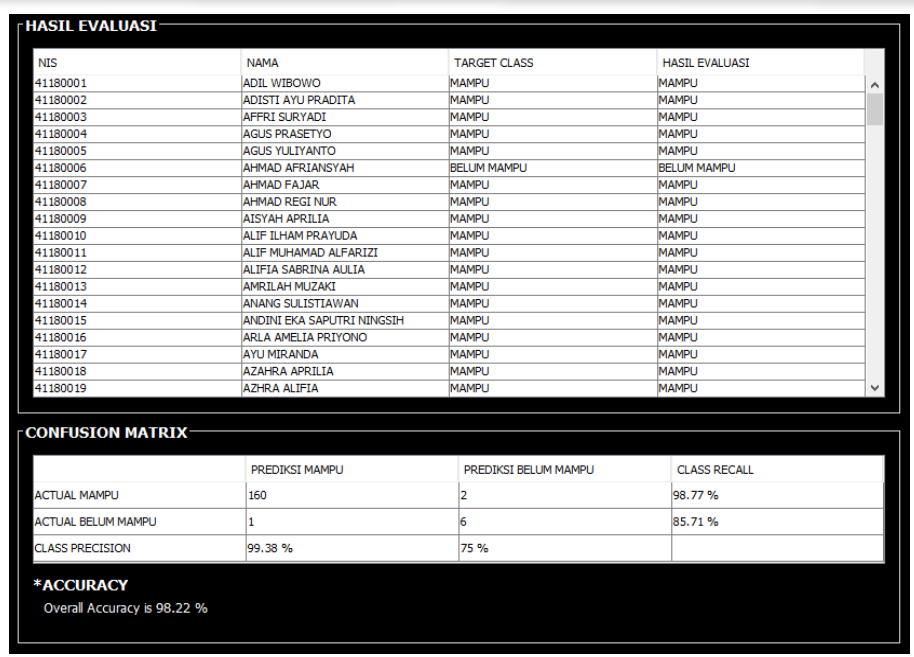

Gambar 11 Hasil Pengujian K=3 Kelas XII

Dari hasil confusion matrix yang didapatkan pada gambar 11 maka peneliti dapat mengihitung nilai dari akurasi, Precision, dan Recall sebagai berikut :

Precision

$=160 /(160+1)$

$=160 / 161=0.9938=99.38 \%$

Recall

$=160 /(160+2)$

$=160 / 160=0.9877=98.77 \%$

Akurasi

$=160+6 /(160+6+1+2)$

$=166 / 169=0.9822=98.22 \%$

$$
=\mathrm{TP} /(\mathrm{TP}+\mathrm{FP})
$$

$$
=\mathrm{TP} /(\mathrm{TP}+\mathrm{FN})
$$

$$
=\mathrm{TP}+\mathrm{TN} /(\mathrm{TP}+\mathrm{TN}+\mathrm{FP}+\mathrm{FN})
$$

\section{Pengujian Number of Nearest Neighbor $(K)=5$ Kelas XII}

Hasil dari pengujian menggunakan algortima K-Nearest Neighbor menggunakan number of Nearest Neighbor $(\mathrm{K})=5$ Pada Kelas XII dengan 521 data model dan 169 data uji mendapatkan hasil nilai aktual mampu yang di prediksikan mampu ( TP ) sebanyak 165 Siswa, nilai aktual mampu yang di prediksikan belum mampu ( FN ) sebanyak 1 siswa, Sementara nilai actual belum mampu yang di prediksikan mampu ( FP ) sebanyak 1 siswa dan nilai actual belum mampu yang di prediksikan belum mampu ( TN ) sebanyak 42 siswa yang dapat di lihat pada gambar 12.

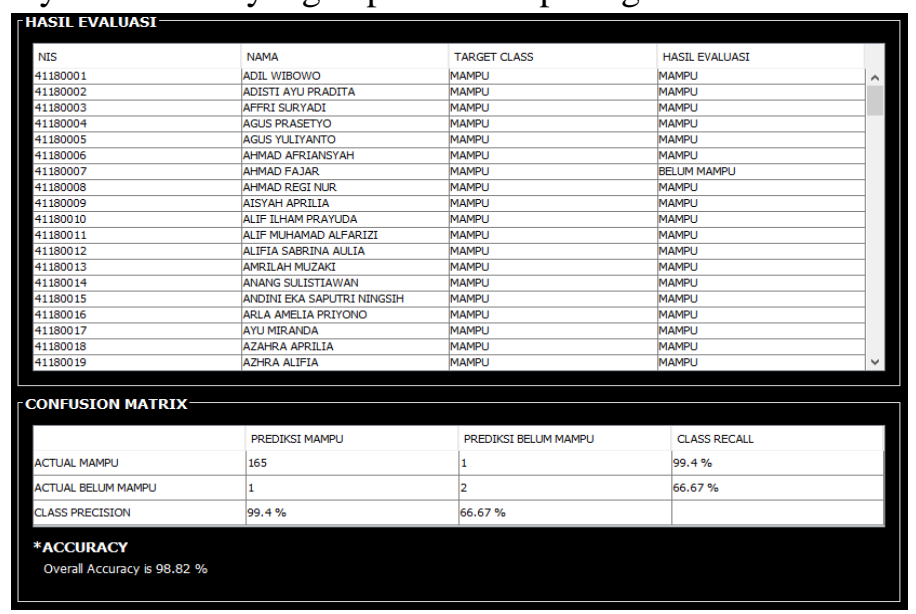

Gambar 12 Hasil Pengujian K=5 Kelas XII

Dari hasil confusion matrix yang didapatkan pada gambar 12 maka peneliti dapat mengihitung nilai dari akurasi, Precision, dan Recall sebagai berikut :

Precision $=\mathrm{TP} /(\mathrm{TP}+\mathrm{FP})$

$=165 /(165+1)$

$=165 / 166=0.994=99.4 \%$ 
Recall

$=165 /(165+1)$

$=165 / 166=0.994=99.4 \%$

Akurasi

$=165+2 /(165+2+1+1)$

$=167 / 169=0.9982=99.82 \%$

$$
=\mathrm{TP} /(\mathrm{TP}+\mathrm{FN})
$$

$$
=\mathrm{TP}+\mathrm{TN} /(\mathrm{TP}+\mathrm{TN}+\mathrm{FP}+\mathrm{FN})
$$

\section{Klasifikasi Algoritma Nä̈ve Bayes}

Klasifikasi menggunakan Algoritma Nä̈ve bayes berfungsi untuk memprediksi kemampuan siswa/I dalam bersaing didunia kerja menggunakan dataset yang belum memiliki keterangan mampu dan belum mampu. data model yang digunakan dalam pengujian ini merupakan dataset terdapat pada database, serta dataset uji yang digunakan dalam pengujian ini menggunakan 497 data yang berasal dari tahun ajaran 2020/2021 Kelas Kelas XII. hasil dari klasifikasi Algoritma Nä̈ve Bayes dapat di lihat pada gambar berikut.

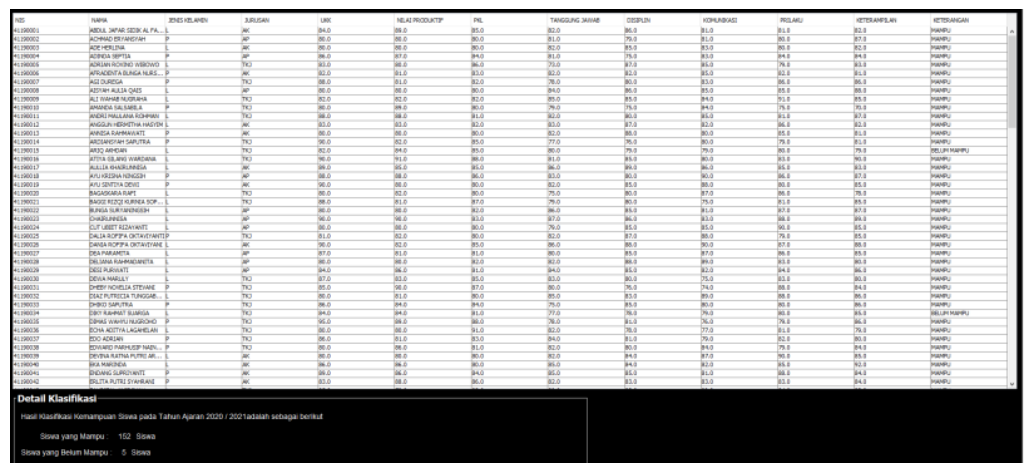

Gambar 13 Hasil Klasifikasi Algoritma Naïve Bayes Kelas XII

Hasil dari pengklasifikasian Kelas XII menggunakan algoritma Nä̈ve bayes mendapati hasil siswa yang di nyatakan mampu terdapat 163 siswa dan yang di nyatakan belum mampu terdapat 6 Siswa dapat dilihat pada gambar 14. Hasil dari pengklasifikasian dapat di save untuk di masukan kedalam database serta akan di lakukan pengujian dengan data model untuk dapat melihat nilai dari akurasi, Precision dan Recall yang di hasilkan.

\section{Pengujian Algoritma Nä̈ve Bayes}

Pengujian menggunakan Algoritma Nä̈ve Bayes Menggunakan 521 Data Model dan Data Uji

\begin{tabular}{|c|c|c|c|c|}
\hline \multicolumn{5}{|l|}{ HASIL EVALUASI } \\
\hline NIS & NAMA & TARGET CLASS & HASIL NAIVE BAYES & \\
\hline 41200001 & ABELLA SYAHLA TALITHA & MAMPU & MAMPU & A \\
\hline 41200002 & ACHMAD ZAIDAN & MAMPU & MAMPU & \\
\hline 41200003 & ADE IHAH SOLIHAH & BELUMM MAMPU & BELUMM MAMPU & \\
\hline 41200004 & ADIMAS RESTU RAMAD... & MAMPU & MAMPU & \\
\hline 41200005 & ADINDA VANIA KINANTI & MAMPU & MAMPU & \\
\hline 41200006 & AISYAH ALUSMAYANTI & MAMPU & MAMPU & \\
\hline 41200007 & AJENG PRAMESWARI & MAMPU & MAMPU & \\
\hline 41200008 & ALLESANDRO BAGINTA ... & MAMPU & MAMPU & \\
\hline 41200009 & ALSYTRA SUSANTI METI... & MAMPU & MAMPU & \\
\hline 41200010 & AMBARSRIRANI & MAMPU & MAMPU & \\
\hline 41200011 & ANGGUN NUR ARIFIANI & MAMPU & BELUM MAMPU & \\
\hline 41200012 & ANISA ZAHWA AZZAHROO & MAMPU & MAMPU & \\
\hline 41200013 & ANJANI KRRANA LARASATI & 1 MAMPU & MAMPU & \\
\hline 41200014 & ANNADIRA NABTLLA SARI & MAMPU & MAMPU & \\
\hline 41200015 & ASRI SETIANINGSIH & MAMPU & MAMPU & \\
\hline 41200016 & ATTKA RIZKI APRILIYANTI & MAMPU & MAMPU & \\
\hline 41200017 & AUDIA CAHYANI & MAMPU & MAMPU & \\
\hline 41200018 & AULIA CAVITA AZHAR & MAMPU & MAMPU & \\
\hline 41200019 & AULIA RETNO WULANDARI & IMAMPU & MAMPU & \\
\hline \multicolumn{5}{|c|}{ CONFUSION MATRIX - } \\
\hline & PREDIKSI MAMPU & PREDIKSI BELUM MAMPU & CLASS RECALL & \\
\hline ACTUAL MAMPU & 162 & 4 & $97.59 \%$ & \\
\hline ACTUAL BELUM MAMPU & 0 & 5 & $100 \%$ & \\
\hline CLASS PRECISION & $100 \%$ & $55.56 \%$ & & \\
\hline \multicolumn{5}{|c|}{ *ACCURACY } \\
\hline \multicolumn{4}{|c|}{ Overall Accuracy is $97.66 \%$} & \\
\hline
\end{tabular}
menggunakan tahun ajaran 2020/2021 Kelas XII dengan total 169 data.

Gambar 14 Dataset Model dan Dataset Uji Algortima Naive Bayes 


\section{Pengujian Algortima Nä̈ve Bayes Kelas XII}

Hasil dari pengujian menggunakan algortima Naïve Bayes pada Kelas XII dengan data model 521 data dan data uji menggunakan 169 data mendapati hasil nilai aktual mampu yang di prediksikan mampu ( TP ) sebanyak 156 Siswa, nilai aktual mampu yang di prediksikan belum mampu ( FN ) sebanyak 7 siswa, Sementara nilai aktual belum mampu yang di prediksikan mampu ( FP ) sebanyak 2 siswa dan nilai aktual belum mampu yang di prediksikan belum mampu ( TN ) sebanyak 4 siswa yang dapat di lihat pada gambar 15 .

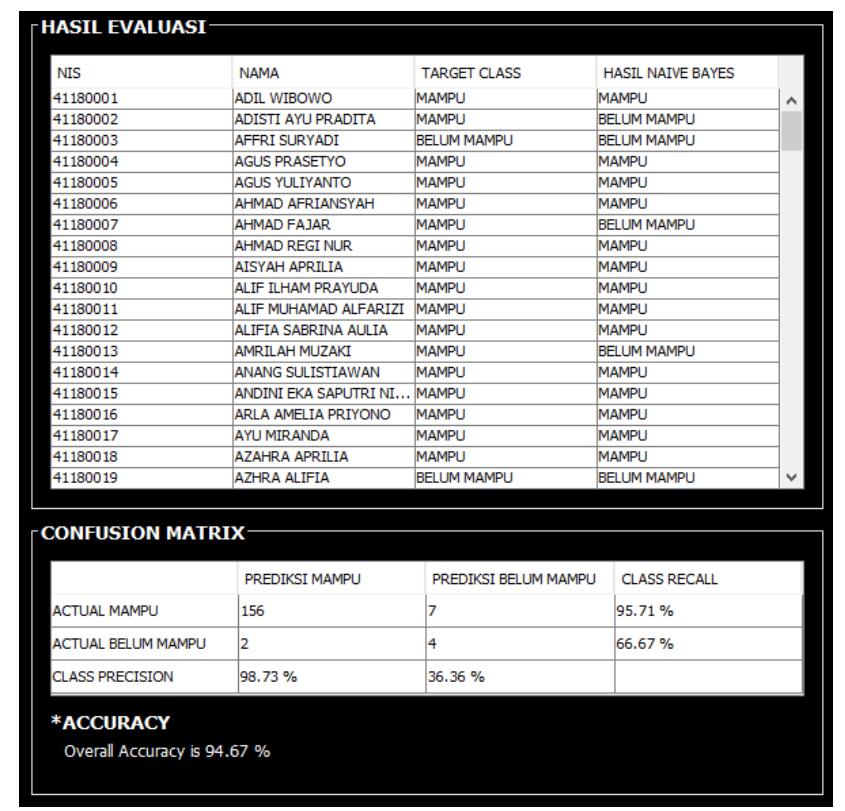

Gambar 15 Hasil Hasil Pengujian Algortima Naïve Bayes Kelas XII

Dari hasil confusion matrix yang didapatkan pada gambar 15 maka peneliti dapat mengihitung nilai dari akurasi, Precision, dan Recall sebagai berikut :

Precision $=\mathrm{TP} /(\mathrm{TP}+\mathrm{FP})$

$=156 /(152+2)$

$=152 / 154=0.9873=98.73 \%$

Recall

$=156 /(156+7)$

$=156 / 163=0.9571=95.71 \%$

Akurasi

$=156+4 /(156+4+2+7)$

$=160 / 169=0.9467=94.67 \%$

$$
=\mathrm{TP} /(\mathrm{TP}+\mathrm{FN})
$$

$=\mathrm{TP}+\mathrm{TN} /(\mathrm{TP}+\mathrm{TN}+\mathrm{FP}+\mathrm{FN})$

\section{KESIMPULAN}

Berdasarkan hasil pengujian yang telah dijabarkan diatas Tujuan dari penelitian ini adalah untuk memprediksi kemampuan siswa dan siswi SMK Yadika 5 Pondok aren falam bersaing di dunia kerja menggunakan perbandingan algoritma naïve bayes dan k-nearest. Berdasarkan pengujian yang telah dilakukan dalam penelitian ini mendapati hasil bahwa Algortima Nä̈ve Bayes memiliki Akurasi 97.66 $\%$, Nilai Precision 100\%, dan Nilai Recall 97.59\% sedangkan Algortima K-Nearest Neighbor mendapati hasil Nilai Akurasi 98.22 \%, Nilai Precision 99.38\%, Nilai Recall $98.77 \%$. 


\section{DAFTAR PUSTAKA}

[1] Buani, D.C. P. (2016). Optimasi Algortima Naïve bayes dengan menggunakan Algoritma Genetika untuk prediksi Kesuburan ( Fertility). Jurnal Evolusi, 4(1), pp. 54-63.

[2] Ginantra, N., Wijaya, F., dkk. 2021. Data Mining dan Penerapan Algoritma. Medan : Kita Menulis

[3] Khoirunnisa, Susanti, L., Rokhmah, I. T., and Stianingsih, L. (2020). Prediksi Siswa SMK AlHidayah Yang Masuk Perguruan Tinggi Dengan Metode Klasifikasi. Jurnal Informatika. 8(1), pp. 26-33.

[4] Kurniawan, E. D., and Mufti. (2018). Implementasi Algoritma K-Nearest Neighbor Dengan Metode Klasifikasi dan Pengukuran Jarak Manhattan Distance Untuk Prediksi Kelulusan UN Berdasarkan Hasil Nilai Tryout Berbasis Java Desktop Pada SMA Harapan Jaya 2. Jurnal Teknik Informatika. 1(1), pp. 76-81.

[5] Kurniawan. (2018). Perbandingan Algoritma Naive Bayes dan C.45 Dalam Klasifikasi Data Mining. Jurnal Teknologi Informasi dan Ilmu Komputer. 5(4), pp. 455-464.

[6] Kusuma, L. W. (2019). Prediksi Kemampuan Lulusan SMK Untuk Dapat Bersaing di Dunia Kerja Dengan Menggunakan Naive Bayes: Studi Kasus SMK Buddhi Tangerang. Jurnal Algor. 1(1), pp. 56-63.

[7] Mabrur, A. G., and Lubis, R. (2012). Penerapan Data Mining Untuk Memprediksi Kriteria Nasabah Kredit. Jurnal Komputer dan Informatika. 1(1), pp. 53-57.

[8] Malik, A. M., and Sibarani, A. J. P. (2018). Aplikasi Prediksi Kelulusan Ujian Nasional Menggunakan Algoritma K-Nearest Neighbor Dengan Pengukuran Jarak Manhattan Distance. Jurnal Teknik Informatika. 1(2), pp. 829-835.

[9] Mujiasih, S. (2011). Pemanfaatan Data Mining Untuk Prakiraan Cuaca. Jurnal Meteorologi dan Geofisika. 12(2), pp. 189-195.

[10] Munanda, W., A.(2020). Klasifikasi Peminatan Siswa Dengan Metode K-Nearest Neighbor (Studi Kasus SMP Negeri 1 Pabuaran ) Diss. University of Technology Yogyakarta.

[11] Mustafa, M. S., Ramadhan. M. R., and Thenata, A. P. (2017). Implementasi Data Mining untuk Evaluasi Kinerja Akademik Mahasiswa Menggunakan Algoritma Naive Bayes Classifier. Citec Journal. 4(2), pp. 151-162.

[12] Nofriansyah, D., Erwansyah, K., and Ramadhan, M. (2016). Penerapan Data Mining Dengan Algoritma Naive Bayes Clasifier Untuk Mengetahui Minat Beli Pelanggan Terhadap Kartu Internet XL. Jurnal Saintikom. 15(2), pp. 81-92.

[13] Ridwan, M., Suyono, H., and Sarosa, M. (2013). Penerapan Data Mining Untuk Evaluasi Kinerja Akademik Mahasiswa Menggunakan Algoritma Naive Bayes Classifier. Jurnal EECCIS. 7(1), pp. 59-64.

[14] Saleh, A. (2015). Implementasi Metode Klasifikasi Naive Bayes Dalam Memprediksi Besarnya Penggunaan Listrik Rumah Tangga. Citec Journal. 2(3), pp. 207-217. 